\title{
Adsorptive Desulfurization of Liquid Fuels Using Na-Bentonite Adsorbents
}

\author{
Fatma Dheif Ali \\ Chemical Engineering Department, Al-Nahrain University, Bgahdad, IRAQ \\ fatmadheifali@gmail.com \\ Received: 24-Sep.-2017 \\ Revised: 13-Nov.-2017 Accepted: 18-Jan.-2018 \\ http://doi.org/10.29194/NJES21020248
}

\begin{abstract}
In this work, model fuel (Thiophene in hexane) was treated for sulfur removal by adsorptive desulfurization method using modified bentonite with sodium (Na-B) adsorbent. Batch and continuous mode were used in this study. Several operating parameters such as initial thiophene concentration of 250 to $2000 \mathrm{mg} / \mathrm{L}$, adsorbent dose 0.1 to $0.8 \mathrm{~g} / \mathrm{ml}$ were studied for sulfur removal \%. Also a comparison between raw and modified bentonite was performed in this study. In continuous mode, a packed bed of Na-B adsorbent column was used at constant initial thiophene concentration and liquid hourly space velocity (LHSV) to study the breakthrough curve of thiophene. The results showed that Na-B adsorbent was better than raw bentonite in removal of sulfur components. The removal percentages was $67,75,87$,and $91 \%$ for $500 \mathrm{mg} / \mathrm{L}$ initial thiophene concentration using adsorbent dose $0.1,0.2,0.4$ and $0.8 \mathrm{~g} / \mathrm{ml}$ respectively , and $87,75,57$, and $53 \%$ for adsorbent dose of 0.2 $\mathrm{g} / \mathrm{ml}$ using initial thiophene concentration of 250 , 500,1000 , and $2000 \mathrm{mg} / \mathrm{L}$ respectively. It was concluded that when increase the dose of adsorbent, the removal of sulfur increase , and when increase the initial concentration the removal decrease.
\end{abstract}

Keywords: Bentonite; Clay; adsorption, desulfurization; modified bentonite.

\section{Introduction}

Now a day the crude oil is the most significant exporter of energy. It should be treat from impurities content of petroleum product. It is the major source of gasoline, jet and diesel fules. The nitrogen and sulfur content of these fuels may be major environmental problems, by conversion to NOx and Sox respectively in internal combustion toxic[1].These toxic compounds leads to acid rains formation , smog, dry deposition and air pollution, which affect the human health and environment [2].

In crude oil processing, partically in catalytic conversion processes, presence of sulfur compound could cause several problems such as catalyst deactivation and corrosion in equibments like pumps, pipes, and furnaces [3].
The acceptable sulfur content in USA is 30 ppm for gasoline and $15 \mathrm{ppm}$ for diesel oil, while in EU the acceptable sulfur content is $10 \mathrm{ppm}$ for gasoline and diesel, so that to reach this amount of sulfur content, deep desulfurization have been applied using several techniques such as: extractive desulfurization, bio desulfurization, photochemical desulfurization, chemical oxidation, and adsorptive desulfurization. The hydrosulfurization (HDS) disadvantages are an expensive and do not work efficiently in ultra deep desulfurization ranges less than $100 \mathrm{ppm}$ of sulfur content [4].

Adsorptive desulfurization is very efficient method for removal of sulfur compounds from fuels due to several advantages such as mild conditions pressure and temperature, low cost, and ease of regeneration. Many adsorbents may be considered for adsorptive desulfurization process such as activated carbon, active alumina, silica, metal oxide, montmorillonite-clay, and zeolite [5].

Alhooshani et al., was studied a simple model of adsorption desulfurization of model fuel oil on modified metal oxides. Zinc oxide used for sulfur removal from model fuels by deep desulfurization process, around $60-80 \%$ desulfurization was achieved at several conditions and optimized conditions [6].

Ahmad et al., studied the adsorptive desulfurization of kerosene and diesel oil through different metals impregnated montmorollonite clay (MMT) in batch operation mode. The results show the impregnated MMT has high desulfurization efficiency than original MMT and $77 \%$ maximum desulfurization in the case of diesel and were obtained $76 \%$ maximum desulfurization for kerosene was at room temperature [7].

$\mathrm{Bu}$ et al., prepared four types of activated carbon from the sources Apricot, Pitch, wood and Coconut. The obtained surface areas of the prepared carbons were varying between 713 $1403 \mathrm{~m}^{2} / \mathrm{g}$. They studied adsorption desulfurization using model fuel (consisted of 4,6-dimethyldibenzothiophene, and monoaromatic, diaromatic and triaromatic compounds to hexadecane They obtained $96 \%$ of the sulfur percent removal [8]. 
Nano particle adsorbents were also used recently for adsorptive desulfurization, for example Khodadadi et al., investigated the capability of $\mathrm{CuO}$ nanoparticle as an adsorbent for desulfurization of diesel fuel in batch experiments. They studied the effect of contact time ,temperature, contact time, agitation effect on the adsorption capacity and adsorbent dose. The results show high activity desulfurization, the sulfur content reduced from 250 ppm S to about zero in less than 1 min [9].

Xiaolin and Le Zheting investigated the sulfur compounds removal process by bentonite clay loaded with silver nitrite as an adsorbent for treatment model gasoline. They stated that the supported bentonite clay has partial-amorphous nature which gives mesoporosity for a wide range of pore sizes. Several parameters were considered for affecting the sulfur removal efficiency such as: backing temperature, $\mathrm{Ag}^{+}$loading percent and the adsorption temperature. The desulfurization efficiency was enhanced by increasing the Ag + loading and the best result was obtained at a silver loading of $7 \mathrm{m \%}$ [10].

In this study liquid model fuel (thiophene in nhexane) was treated by modified Bentonite. The main goal of this study is to investigate the effect of modified bentonite with sodium for sulfur removal in batch and continuous mode using adsorptive desulfurization techniques.

\section{Experimental}

\subsection{Materials}

Bentonite was analyzed and supplied by the Iraq Geological Survey. This clay is available in Basheera Valley in Al-Rutba region. Sodium Chloride AR (Na-Cl) molecular weight 58.44 $\mathrm{g} / \mathrm{mol}$ from certified company. n-hexane $\left(\mathrm{C}_{6} \mathrm{H}_{14}\right.$, purity $\geq 99 \%$, supplied from Sigma-Aldrich company, density, $0.871 \mathrm{gm} / \mathrm{cm}^{3}$ at $16{ }^{\circ} \mathrm{C}$; boiling point, $74.1{ }^{\circ} \mathrm{C}$; and molecular weight, $86.18 \mathrm{~g} / \mathrm{mol}$ ) mixed with various amounts of thiophene $\left(\mathrm{C}_{4} \mathrm{H}_{4} \mathrm{~S}\right.$ of $99.9 \%$ purity, supplied from Fluka Chemie AG Company, density, 1.071 $\mathrm{gm} / \mathrm{cm}^{3}$ at $16{ }^{\circ} \mathrm{C}$; boiling point, $84.1{ }^{\circ} \mathrm{C}$ and molecular weight, 84 ; as a sulfur source.

\subsection{Characterization of Adsorbent}

(XRD) powder diffraction was used to describe the crystallinity of the adsorbent Na-B. XRD-6000 (type Bruker D2 PHASER), with (2e) angle of range $20^{\circ}-80^{\circ}$ was used. The XRD pattern of raw Bentonite (B) and modified sodium Bentonite (Na-B) were carried in Baghdad University, College of Science, Geological department. The Horiba sulfur-in-oil analyzer (SLFA2100) was used to find the sulfur concentration of fuel

\subsection{Preparation of (Na-B) Adsorbent:}

About 20g of the Bentonite was agitated for $12 \mathrm{hr}$ with $1 \mathrm{~L}$ of $2.0 \mathrm{M} \mathrm{NaCl}$ solution to displace commutable cation with $\mathrm{Na}^{+}$then centrifuged and washed by distilled water three times until $\mathrm{Cl}^{-}$was removed. The Sodium Bentonite (Na-B) was dried at $100{ }^{\circ} \mathrm{C}$ for $48 \mathrm{hr}$ and sieved to gain $75 \mu$ particle diameters.

\subsection{Batch desulfurization study}

Model (Thiophene $\left(\mathrm{C}_{4} \mathrm{H}_{4} \mathrm{~S}\right)$ in n-hexane $\left(\mathrm{C}_{6} \mathrm{H}_{14}\right)$ ) was firstly desulfurized in batch mode using both Bentonite and Na-Bentonite. Bentonite (0.2g) was conducted using different initial concentration (250,500,1000 and 2000) ppm and then modified Bentonite was used as adsorbent for sulfur removal from model liquid fuel thiophene in hexane of different various parameter such initial concentration $(250,500,1000,2000) \mathrm{ppm}$ and adsorbent dose $(0.1,0.2,0.4,0.8) \mathrm{g} / \mathrm{ml}$ for each bentonite and modified bentonite. The adsorption experimental were carried out using $20 \mathrm{ml}$ of liquid model fuel shacked for $5 \mathrm{hr}$.

The percentages of desulfurization were calculated by the equation:

$$
\text { Desulfurization } \%=\frac{\mathrm{C}_{\mathrm{in}}-\mathrm{C}_{\text {out }}}{\mathrm{C}_{\mathrm{in}}} * 100
$$

\subsection{Continuous desulfurization study}

In this study the experiment of desulfurization for fuel were utilized to study the effect of operation time at constant bed height adsorbent dose and initial concentration in batch model. Then continuous model was used as second branch for fuel desulfurization. It detected the removal of sulfur for several (Na-B) adsorbent with contact time. In this mode, affixed bed of adsorbent (Na-B) was filled in a column of $20 \mathrm{~cm}$ in height and $12 \mathrm{~mm}$ (ID). The $0.5 \mathrm{~cm}$ height fiber class put in the bottom of the column to back the bed of adsorbent and $5 \mathrm{~g}$ of adsorbent full of in the column. The run was carried out at the room temperature and Liquid hourly space velocity (LHSV) $2 \mathrm{hr}^{-2}$, 1L separator funnel was used as fuel feed tank, and the calibration tube was used for checking the flowrate. Both calibration burette and funnel were put at the top of the column. The fuel feed was flowing to the column at constant flow. Fig. 1 shows the fixed bed adsorbent unit. The collected samples at various time intervals for analysis of sulfur unit saturation were achieved.

\section{Results and Discussion \\ 3.1 XRD Characterization}

The XRD of Bentonite and Sodium Bentonite is shown in Figures 2,3. The XRD pattern of Na$\mathrm{B}$ sample is rich in montmorillonite which leads to reflection at $2 \theta=12^{\circ}$ effected by sodium insertion, as seen by the difference in Fig 3. at the same point $2 \mathrm{\theta}=12^{\circ}$ the broadening of intensity (1600) reversal that the order structure is ruptured as a result of intercalation of sodium [11]. 


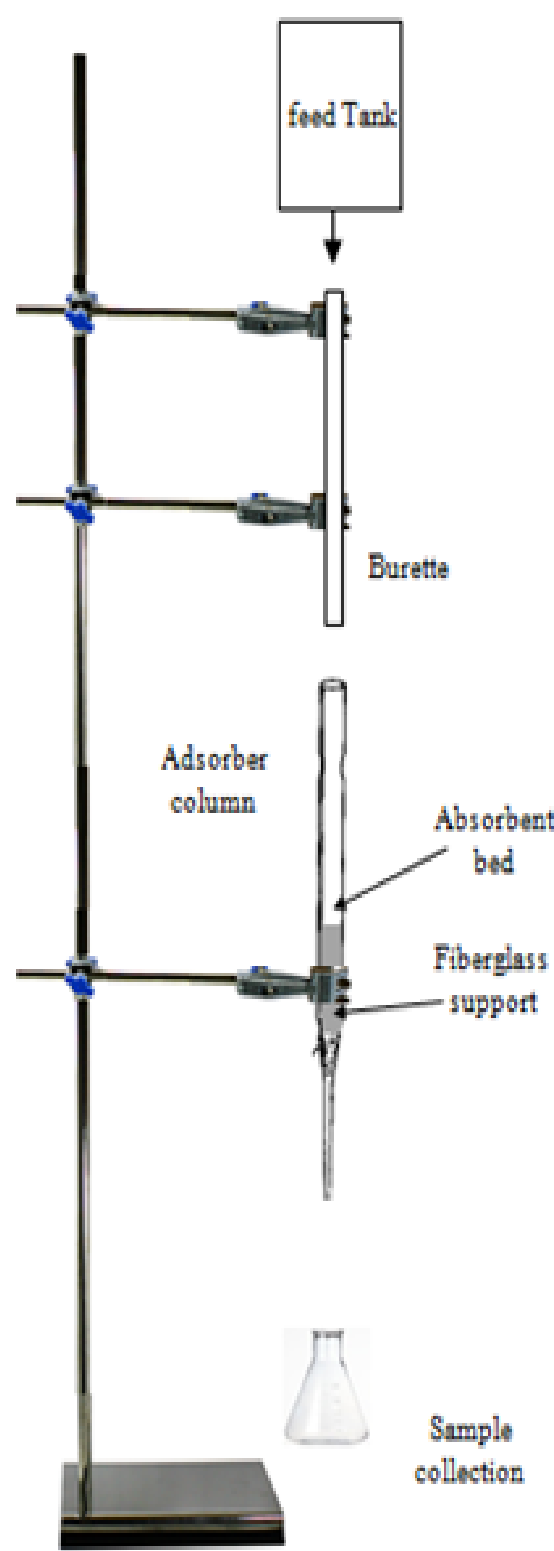

Figure 1: The fixed bed adsorbent unit used in continuvus sudy

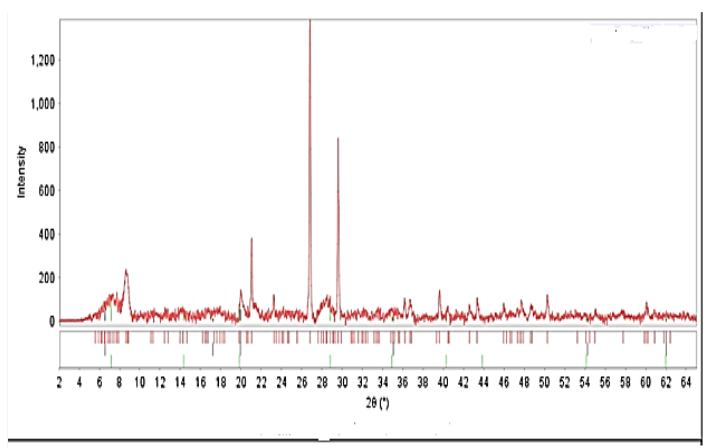

Figure 2:.The XRD pattern of Sodium Bentonit (Na-B)

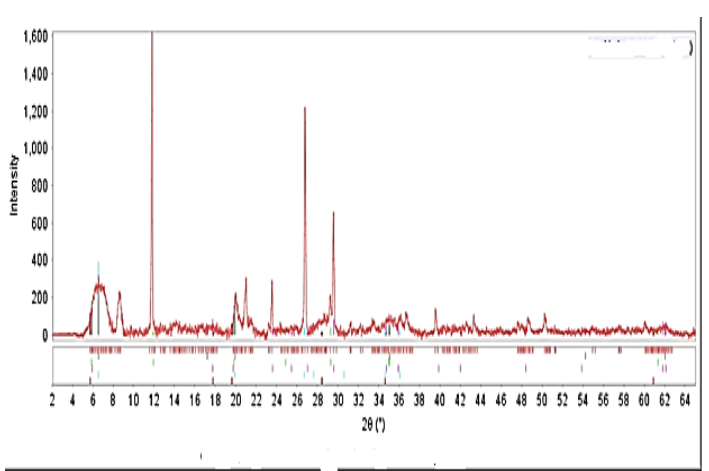

Figure 3: XRD pattern of Bentonite (B)

\subsection{Batch Desulfurization}

\subsubsection{Effect of Initial Concentration:}

The effect of initial concentration of the thiophene for the removal of sulfur component has been recorded in Figure 4, shows that the increase in initial concentration leads to decrease the removal percentage of sulfur component. This can be attributable to that all the catalysts have a limited number of active sites on its surface, which become saturated at a certain concentration [12].

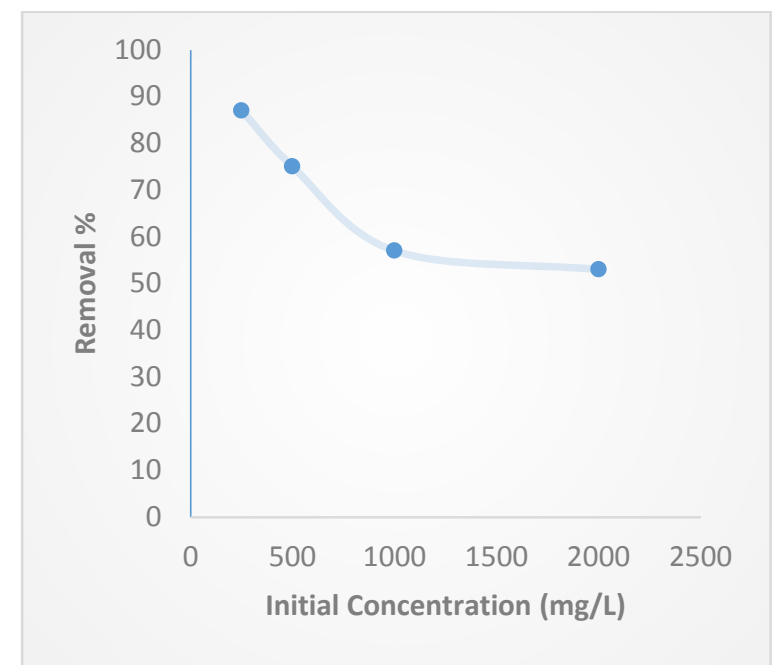

Figure 4: Effect of Initial Concentration (Batch study)

\subsubsection{Effect of Adsorbent Dose:}

The desulfurization of thiophene was also tested with various quantity of modified Bentonite ie $(0.1,0.2,0.4,0.8) \mathrm{g}$. The effect of adsorbent dose on desulfurization is shown in Figure5. the increase in adsorbent dose with increase percentage of sulfur removal can be attributed to the availability of greater surface area and therefore a larger number of adsorption active sites. When using low catalyst dose (i.e. available surface area is less than optimum or required), the catalyst surface becomes saturated with thiophene and therefore the large concentration of residual thiophene remained in the solution. Continuous increasing in catalyst dose, more surface area, and active sites leads to increase in thiophene removal 
because the thiophene uptake increased by a more available catalyst. When using catalyst dose greater than required, the percent removal of thiophene become nearly constant. [13]

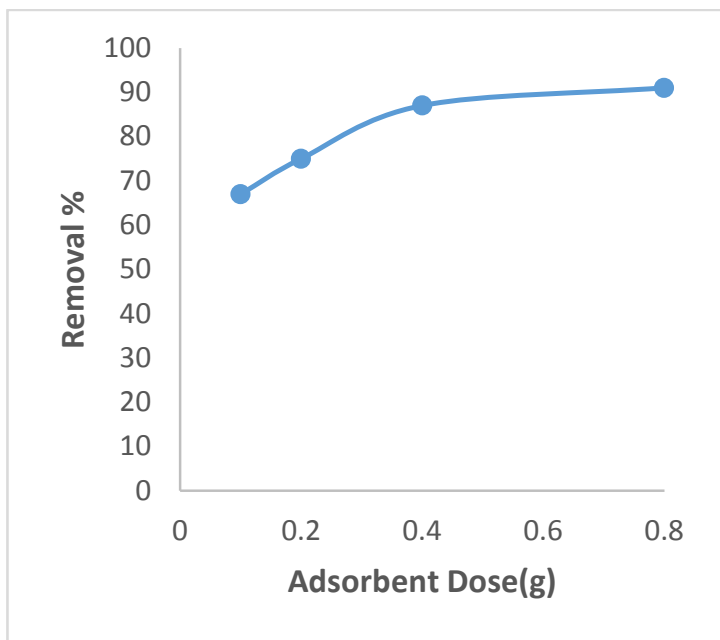

Figure 5: Effect of Adsorbent Dose

\subsubsection{Comparison between $\mathrm{B}$ and $\mathrm{Na}-\mathrm{B}$ as adsorbents}

The experiment where test with various initial concentration (250,500,1000,2000 ppm) and adsorbent dose of (0.2g) Bentonite (B) and Modified Bentonite (Na-B) are presented in Figure6, shows that the removal of ( $\mathrm{Na}-\mathrm{B}$ ) for sulfur component where better than the removal of (B) because the increase of activated group on the surface of the adsorbent [14] .

\subsection{Continuous Desulfurization:}

Other test of the capacity of adsorption for Na-B as adsorbent in continuous desulfurization of Thiophene was done at room temperature, constant liquid hourly space velocity (LHSV) of 2 $\mathrm{hr}^{-1}$ and the bed height of $20 \mathrm{~cm}$. Fig.7, represent the curve of breakthrough for sulfur component adsorption from thiophene on (Na-B) adsorbent in expression (Ct/Ci) vs. time. The exhaustive point time was $6 \mathrm{hr}$. This related to the $\mathrm{Na}-\mathrm{B}$ has specific acid-base interaction and $\pi$-complexation between $\mathrm{Na}^{+}$and thiophene molecules [15].

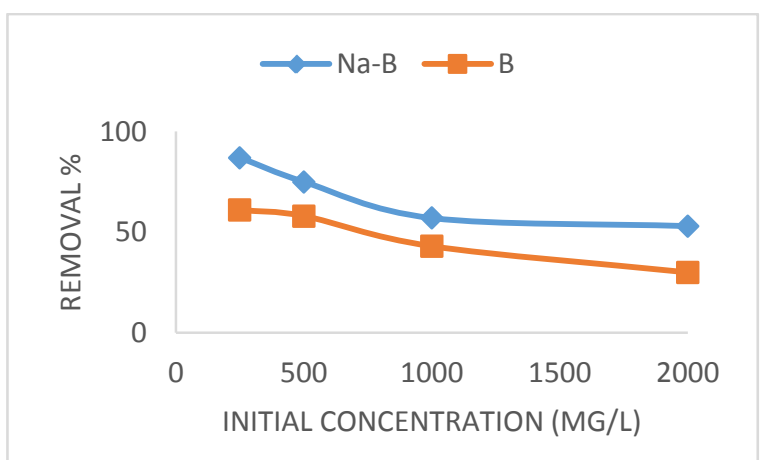

Figure 6: Comparison between modified (Na-B) and raw bentonite(B) as Adsorbents

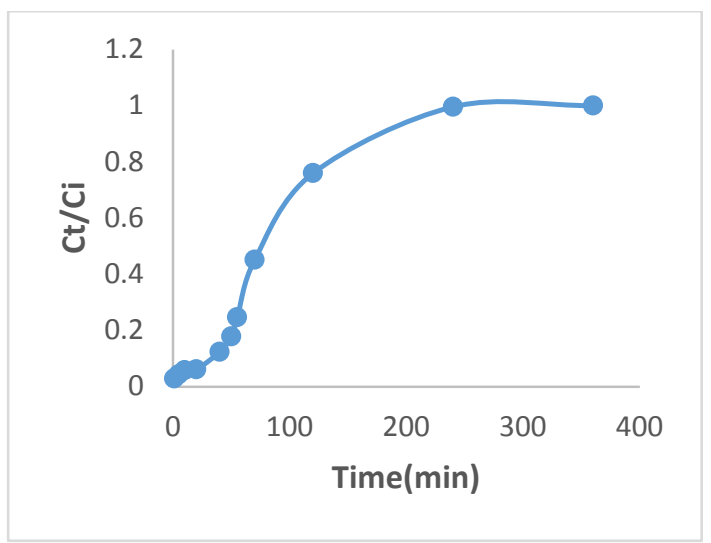

Figure 7: The breakthrough curve for thiophene adsorption from liquid fuel on (Na-B) adsorbent

\section{Conclusion}

In this study the results show that the adsorbent of modified bentonite $\mathrm{Na}-\mathrm{B}$ for desulfurization of thiophene have much higher adsorption capacity than bentonite clay due to the enhancement of adsorption efficiency by $\mathrm{Na}^{+}$on bentonite. The percentage of desulfurization increase with increase an adsorbent dose from 67 to 90 and decrease with increase initial concentration from 87 to 53 in batch and contintinuous mode in time of exhaustive point $6 \mathrm{hr}$.

\section{References}

1. Rang, H., Kann, J., \& Oja, V. (2006), "Advances in desulfurization research of liquid fuel” ,Oil Shale, 23(2), 164-176

2. Song, C., \& Ma, X. (2004), “Ultra-deep desulfurization of liquid hydrocarbon fuels Chemistry and process”, International Journal of Green Energy, 1(2), 167-191.

3. Adeyi, A. A., \& ABERUAGBA, F. (2012), "Comparative analysis of adsorptive desulphurization of crude oil by manganese dioxide and zinc oxide", Research Journal of Chemical Sciences, 2(8), 14-20.

4. Velu, S., Song, C., Engelhard, M. H., \& Chin, Y. H. (2005)," Adsorptive removal of organic sulfur compounds from jet fuel over K-exchanged $\mathrm{NiY}$ zeolites prepared by impregnation and ion exchange”, Industrial \& engineering chemistry research, 44(15), 5740-5749

5. Mužic, M., \& Sertić-Bionda, K. (2013), "Alternative Processes for Removing Organic Sulfur Compounds from Petroleum Fractions”, Chemical and Biochemical Engineering Quarterly, 27(1), 101-108.

6. Alhooshani, K. R., Siddiqui, N., \& Gondal, T. A. S. M. A., (2013) "Adsorptive desulfurization of model fuel oil using novel metal oxides", .Pap.-Am. Chem. Soc., Div. Energy Fuels Preprints, 58(1), 1024-1025.

7. Ahmad, W., Ahmad, I., Ishaq, M., \& Ihsan, K. (2014)," Adsorptive desulfurization of kerosene 
and diesel oil by Zn impregnated montmorollonite clay”. Arabian Journal of Chemistry.

8. Bu, J., Loh, G., Gwie, C. G., Dewiyanti, S., Tasrif, M., \& Borgna, A. (2011), "Desulfurization of diesel fuels by selective adsorption on activated carbons: competitive adsorption of polycyclic aromatic sulfur heterocycles and polycyclic aromatic hydrocarbons", Chemical Engineering Journal, 166(1), 207-217.

9. Khodadadi A., Torabi angajia M., A. Talebizadeh rafsanjania, A., Yonesib, (2012), "Adsorptive desulfurization of diesel fuel with nano copper oxide (CuO)”, Proceedings of the 4th International Conference on Nanostructures (ICNS4), pp 12-14,March 2012.

10. Xiaolin, T., \& Le Zheting, S. L. (2011), "Deep desulfurization via adsorption by silver modified bentonite”, China Petroleum Processing and Petrochemical Technology, 13, 16-20.

11. Guixia, Z., Hongxia, Z., Qiaohui, F., Xuemei, R., Jiaxing and Xiangke, W, [PP9IYTO(2010),” Sorption of copper "(II) onto super-adsorbent of bentonite-polyacrylamide composites”, Journal of Hazardous Materials, 173, 661-668.

12. Eren, E., and Afsin, B. (2008). Investigation of basic dye adsorption from aqueous onto raw and pre-treated bento $\mathrm{J}$ nite surface. Dyes Pigments, 76, 220-225.

13. Muhammad, I., Siraj, S., Imtiaz, A., Hameed, U., Muhammad, Y., and Alia, A., (2015), "Adsorptive desulfurization of model using untreated, acid activated and magnetite nanoparticle loaded bentonite as adsorbent", Journal of Saudi Chemical Society.

14. Ma, X., Sakanishi, K., \& Mochida, I. (1994), "Hydrodesulfurization reactivities of various sulfur compounds in diesel fuel” ,Industrial \& engineering chemistry research, 33(2), 218-222.

15. Tang, K., Song, L.J., Duan, L.h., Li, X.q., Gui, J.Z., Sun, Z.i., (2008), “ Deep desulfurization by selective adsorption on aheteroatoms zeolite prepared by secondary synthesis”, Fuel Proc. Technol. 89, 1-6.

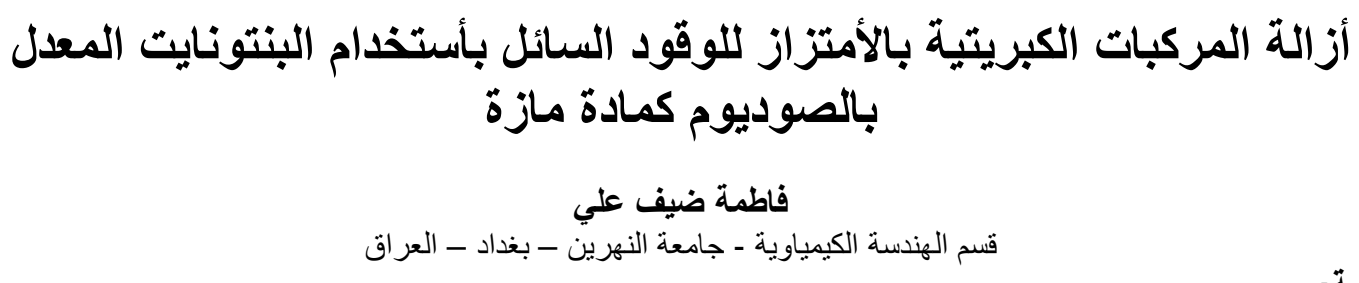

في هذا البحث تم دراسة از الة الكبريت من الوقود النموذجي (مركب الثايوفين في الهكسان)بو اسطة عملية الامتزاز بأستخدام البنتونايت

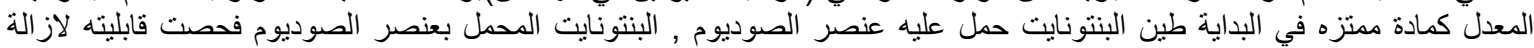

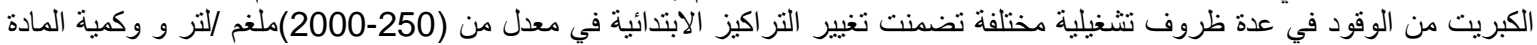

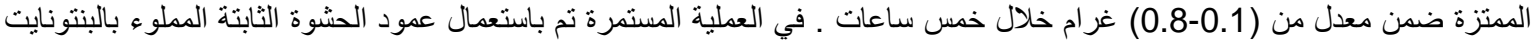

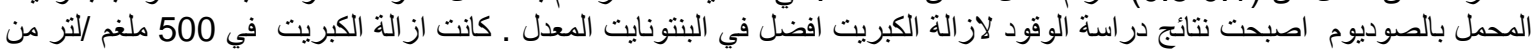

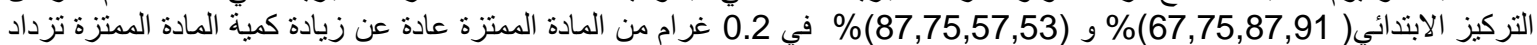
از الة الكبريت و عند زيادة تر اكيز الابتدائية تقل ازالة الكبريت . 
